\title{
INTEGRAÇÃO E DESENVOLVIMENTO NO MERCOSUL: \\ DIVERGÊNCIAS E CONVERGÊNCIAS NAS POLÍTICAS ECONÔMICAS NOS GOVERNOS LULA E KIRCHNER
}

\author{
Javier A. Vadell
}

Bárbara Lamas

Daniela M. de F. Ribeiro

\section{RESUMO}

O início do século XXI é testemunha da ascensão ao poder de novos governos de esquerda e centroesquerda na América do Sul, que apresentam pelo menos duas características em comum: o questionamento das políticas e reformas pró-mercado ocorridas na década anterior e a volta do Estado como ator central da vida econômica. A despeito desse ponto em comum, uma análise mais aprofundada nos permite perceber certa heterogeneidade de natureza programática e organizacional dos novos governos progressistas. Nesse sentido, propomos analisar as respostas dadas por Argentina e Brasil à crise do neoliberalismo, dando especial ênfase às políticas econômicas para o desenvolvimento e suas implicações para a integração regional. Esta análise mais sistemática permite-nos perceber que a Argentina e o Brasil têm feito escolhas distintas no que diz respeito ao tipo de política adotada. O Brasil tem recorrido a práticas mais ortodoxas, como políticas monetárias restritivas para conter as expectativas de inflação, enquanto a Argentina tem preferido medidas heterodoxas, como controle de preços e restrição às exportações, bem como outras políticas de incentivo ao consumo. Em certa medida, a diferença entre as escolhas pode ser atribuída à própria trajetória econômica e política de ambos os países: as reformas pró-mercado, por exemplo, foram mais intensas na Argentina do que no Brasil, o que implicou, no que diz respeito à estrutura produtiva, uma maior desindustrialização e a extinção de algumas instituições desenvolvimentistas.

PALAVRAS-CHAVE: Argentina; Brasil; políticas de desenvolvimento; integração regional; política econômica comparada.

\section{INTRODUÇÃO}

O início do século XXI é testemunha da ascensão ao poder de novos governos de esquerda e centro-esquerda na América do Sul - Néstor Kirchner, seguido por Cristina Fernández de Kirchner, na Argentina; Luiz Inácio Lula da Silva no Brasil; Evo Morales, na Bolívia; Rafael Correa, no Equador; Tabaré Vázquez, no Uruguai; Hugo Chávez, na Venezuela; e, mais recentemente, Fernando Lugo, no Paraguai. Todos apresentam uma característica em comum: o questionamento das políticas e reformas pró-mercado ocorridas na década anterior ${ }^{1}$. Nesse cenário, o Estado retoma algumas responsabilidades que haviam sido transferidas para o mercado nos anos 1990, constituindo um novo padrão de relação entre Estado,

1 O Presidente do Paraguai, Fernando Lugo, tomou posse em 15 de agosto de 2008 e ainda não realizou nenhuma política concreta que indicasse a mesma orientação de seus pares sul-americanos. Contudo, seu discurso durante a campanha presidencial foi nesse sentido. mercado e sociedade. Entretanto, o modelo de desenvolvimento que se afigura ainda não está claramente definido, mesmo que seja possível perceber a reincorporação, na agenda sul-americana, de temas como política industrial, nacionalização de indústrias e de recursos estratégicos e protecionismo.

Ao mesmo tempo, torna-se evidente que a crescente valorização da região na política externa dos países imprime contornos à integração diferentes daqueles desenhados durante a década de 1990, quando esta era mais um instrumento para melhorar a competitividade internacional vis à vis a globalização. A integração regional, nessa nova realidade, passa a ser vista como uma possibilidade não só de incrementar as relações econômicas regionais, mas também de aumentar o poder de barganha da região nas arenas hemisféricas e internacionais (LIMA \& COUTINHO, 2007).

Uma análise mais aprofundada, contudo, permite-nos perceber certa heterogeneidade de natu- 
reza programática e organizacional nos novos governos progressistas. Não há total uniformidade entre as novas políticas adotadas, de modo que é possível notar um nítido contraste entre os caminhos escolhidos pelos países da região, com diversas nuances de intervencionismo e regulação estatal, o que muitas vezes é fruto da própria tradição política local (LIMA \& COUTINHO, 2006, p. 16). Tudo isso tem reflexos no direcionamento das políticas de desenvolvimento de longo prazo, o que pode influenciar a integração regional, haja vista que essas estratégias podem acentuar ou minimizar as assimetrias entre os países.

Nesse contexto, o objetivo deste trabalho é analisar as políticas econômicas de desenvolvimento adotadas pela Argentina, nos governos de Néstor Kirchner e Cristina F. de Kirchner, e pelo Brasil, no governo Luiz Inácio Lula da Silva, e suas implicações para a política externa. Nas conclusões, pretendemos verificar os prováveis desdobramentos dessas políticas sobre a integração regional.

\section{ASCENSÃO DE GOVERNOS PROGRESSIS- TAS AO PODER: DUPLO MOVIMENTO OU DINÂMICA PENDULAR}

Uma boa ferramenta para entender-se a ascensão ao poder de governos progressistas no início do século XXI, na América do Sul, seria o clássico conceito de "duplo movimento", de Karl Polanyi. Segundo o autor, a dinâmica da sociedade moderna basear-se-ia na "ação de dois princípios organizadores da sociedade, cada um deles determinando seus objetivos institucionais específicos, com o apoio de forças sociais definidas e utilizando diferentes métodos" (POLANYI, 2000, p. 163). O primeiro seria o liberalismo econômico, cuja finalidade seria estabelecer um mercado auto-regulável, dependendo do apoio das classes comerciais e usando especialmente o laissez-faire e o livre comércio como métodos. O segundo seria a proteção social, cujo objetivo seria proteger o homem, a natureza e a organização produtiva por meio de instrumentos de intervenção, como legislação protetora e associações restritivas. Em outros termos, as sociedades possuem um mecanismo de autodefesa que se manifesta pela ação da autoridade estatal a partir de um lógica dialética. O duplo-movimento seria um contra-movimento de autodefesa carente, em princípio, de um projeto específico - por sua natureza pragmática - que historicamente se deu em diferentes sociedades, na segunda metade do século XIX, num estágio determinado do desenvolvimento capitalista. Nesse sentido, o contra-movimento no final do século XIX teria sido uma espécie de "reação contra um transtorno que atacava o tecido da sociedade e que teria destruído a própria organização da produção a que o mercado dera vida” (idem, p. 161). Ou seja, o choque entre esses dois princípios seria a chave para entender-se a história social do século XIX e, agora, também a transição do século XX para o XXI -, que se caracterizaria pela alternância de prevalência de um ou outro princípio.

Mais recentemente, Peter Evans (1997) utilizou a metáfora de um pêndulo ideológico para caracterizar essa alternância. Isto é, a pressão pela redução do papel do Estado teria sido uma reação aos prévios "excessos" dos políticos e administradores estatais: o excessivo otimismo sobre as possibilidades do Estado teria sido substituído pelo excessivo pessimismo. Igualmente, o ressurgimento do protagonismo do Estado nacional seria uma reação aos magros resultados sócio-econômicos dos programas liberalizantes.

De uma forma ou de outra, o movimento de resgate do Estado insere-se na busca de modificação do quadro de hegemonia do neoliberalismo, em resposta aos resultados insatisfatórios, sociais e econômicos ${ }^{2}$. Mas esse movimento, como bem argumenta Evans (1996), não se refere ao

2 Os legados da era de ouro das reformas estruturais resumem-se a: 1) endividamento público (interno e externo); 2) grande vulnerabilidade em relação a choques externos e oscilações do mercado financeiro internacional; 3) congelamento de um statu quo excludente; 4) redução e enfraquecimento dos instrumentos de intervenção econômica; 5) estabilidade monetária, em prejuízo do crescimento econômico; 6) desnacionalização do aparato produtivo, transferindo-se a renda do setor público para o setor privado e do setor produtivo para o setor financeiro; 7) elevação das taxas de desemprego e redução dos rendimentos do trabalho (FILGUEIRAS, 2002; LIMA \& COUTINHO, 2006). No campo social, houve piora das condições de trabalho, que se refletiu na qualidade de vida depois que se esgotaram os benefícios da estabilização: o número de contratos temporários cresceu, aumentaram as horas de trabalho, reduziram-se os contratos e a proteção social. Com isso, houve uma tendência de elevação do desemprego aberto no Brasil e na Argentina nos anos 1990, refletindo também no aumento do índice de informalidade ou emprego por conta própria, conforme dados do Instituto Brasileiro de Geografia e Estatística (IBGE) e do Instituto Nacional de Estadística y Censos (Indec). Na Argentina, em 2001, 50\% da população se encontravam em situação de pobreza ou extrema pobreza (GRUGEL \& RIGGIROZZI, 2007). 
resgate de expectativas otimistas e pouco realistas do desenvolvimentismo, que dominaram a configuração do modelo econômico no período posterior à II Guerra Mundial. Ao contrário, como analisam Boschi e Gaitán, não se pode desconsiderar o impacto da experiência sul-americana da década de 1990 sobre o Estado e sua capacidade desenvolvimentista. As medidas realizadas nas últimas décadas do século XX certamente alteraram o aparato estatal, com a instauração de novas modalidades de regulação e de imbricação público-privada (BOSCHI \& GAITÁN, 2008, p. 183). O novo modelo de desenvolvimento que se vem conformando no início do século XXI resgata elementos do desenvolvimentismo cepalino ${ }^{3}$, ao mesmo tempo em que também mantém preocupações centrais para economistas neoclássicos, como estabilidade, disciplina fiscal e importância da iniciativa privada.

É importante mencionar, ainda, que, da mesma forma que as experiências não se repetem no tempo, elas tampouco se repetem em espaços diferentes. Assim como houve uma importante diferença de intensidade e profundidade na realização das reformas estruturais da década de 1990, existem particularidades também na forma como o Estado apresenta-se nesse novo momento na Argentina e no Brasil. Nesse sentido, analisaremos, na próxima sessão, exatamente as semelhanças e as diferenças sobre a forma como se processa a retomada do Estado em ambos os países, dando especial ênfase às políticas macroeconômicas.

Vale notar que a conjuntura internacional nos primeiros anos do século XXI, especialmente depois de 2003, foi bastante favorável, tanto para a Argentina quanto para o Brasil. O preço das commodities bateu recordes sucessivos nos mercados internacionais, devido, entre outros elementos, ao crescimento da China e da Índia, um dos principais fatores que impulsionaram as economias argentina e brasileira. Dados os objetivos deste trabalho, a questão que devemos nos perguntar é: como Argentina e Brasil têm aproveitado - ou aproveitaram - esse momento de bonança?

3 Tal adjetivo refere-se, evidentemente, à Comissão Econômica para a América Latina (Cepal).

\section{O ESTADO NAS POLÍTICAS ECONÔMI- CAS DE DESENVOLVIMENTO}

\section{III.1. Argentina}

Um elemento imprescindível para a análise política da Argentina do século XXI foi a crise política que se instaurou em conseqüência da deterioração das condições econômicas e sociais e dos protestos realizados pela população, incluindo-se saques, vandalismo e forte repressão policial em dezembro de $2001^{4}$. A economia argentina estava praticamente quebrada em 2001. A queda do Produto Interno Bruto (PIB) nos dois últimos trimestres desse ano havia sido de 4,9\% e 10,5\% em relação ao mesmo período do ano anterior, de modo que 2001 fechou com o PIB 4,4\% menor do que o de 2000. Durante todo o ano, o risco de moratória esteve alto, houve fuga de capitais e perda de crédito internacional, situação agravada pelas regulamentações compulsórias para saques bancários, que ficaram conhecidas como corralito e corralón ${ }^{5}$, no final do ano. Eram crescentes os déficits em conta corrente, sustentados pela entrada líquida de capitais por via financeira, mas que implicaram um endividamento em elevação ${ }^{6}$. Tal situação culminou com a renúncia de

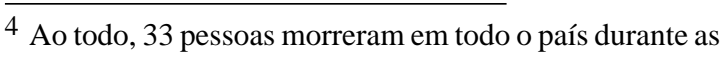
manifestações contra as medidas de austeridade anunciadas para combater a crise de 2001 e 2002. Durante confrontos entre manifestantes e as forças de segurança, houve pilhagem de supermercados e bancos e alguns supermercados começaram a distribuir comida para evitar saques. Os distúrbios levaram ao medo de que as forças de segurança nacional ameaçassem a estabilidade democrática do país no intuito de restaurar a ordem, e acabou resultando no Decreto de Estado de Exceção, emitido pelo presidente Fernando de la Rúa, no dia 19 de dezembro. No dia seguinte, De la Rúa renunciou à presidência (OBSERVATÓRIO POLÍTICO SUL-AMERICANO, 2008).

5 O Corralito consistiu no congelamento dos depósitos em conta-corrente e poupança. O Corralón, por sua vez, foi a medida que congelou o dinheiro depositado em fundos de investimentos e outras aplicações de prazo fixo.

6 Segundo Ferrari e Cunha (2005), no auge da fase “eufórica” do modelo, entre 1992 e 1998, a economia cresceu ao ritmo de $6 \%$ ao ano, acumulando um déficit em transações correntes de mais de US\$ 60 bilhões, financiados por uma entrada líquida de capitais de cerca de US\$ 100 bilhões. Somente em investimento direto externo (valores brutos), o país captou US\$ 60 bilhões no mesmo período, quando da privatização de setores importantes como os de energia, petróleo e telecomunicações. A grave recessão entre 1999 e 2002 não só eliminou os ganhos derivados da euforia do início da conversibilidade, como também agravou a situa- 
diversos presidentes nos últimos dias de 2001. Antes que Eduardo Duhalde assumisse o cargo, em janeiro de 2002, outros três presidentes passaram pela Casa Rosada. Foram cinco presidentes em menos de 20 dias $^{7}$.

Foi esse o contexto que ditou a tônica dos primeiros meses do governo de Eduardo Duhalde, que conseguiu realizar medidas importantes para o restabelecimento da institucionalidade do país, rejeitando os programas ortodoxos de estabilização. Em termos gerais, o governo estabeleceu um conjunto de novas políticas de orientação heterodoxa, de caráter pragmático, inspirado, em parte, pelo que ficou conhecido como Plan Fénix, um programa de ação formulado por economistas da Universidade de Buenos Aires (GRUGEL \& RIGGIROZZI, 2007). Tal plano baseava-se no pressuposto de que o desenvolvimento econômico e a elevação do nível de vida requerem o cumprimento das seguintes condições, entre outras: 1) Estabilidade institucional e política; 2) Aumento do emprego e incorporação da força de trabalho ao processo de crescimento como requisito da integração do tecido social; 3) Funcionamento eficiente e competitivo dos mercados de bens e serviços, financeiros e reais; 4) Equilíbrio macroeconômico sólido embasado em altas taxas de poupança interna e investimento, financiamento genuíno do setor publico, competitividade in-

ção fiscal do setor público, que teve de ampliar o endividamento para fazer frente à perda relativa de capacidade de arrecadação tributária. Entre 1993 e 2002, as rendas do setor público não-financeiro cresceram $11 \%$, e as despesas, 32\%.

7 Depois da renúncia de Fernando de la Rúa, o Presidente do Senado, Ramón Puerta, assumiu o poder e convocou a Assembléia Legislativa, que designou Adolfo Rodriguez Saá como novo Presidente provisório. Saá assumiu no dia 23 e, no mesmo dia, declarou a moratória da dívida externa, mas, com apenas uma semana de governo, Saá renunciou, depois de não obter o consenso dos governadores peronistas para levar adiante um plano de governo que conseguisse acalmar as reclamações da população, que retomou os protestos na Praça de Maio e derrubou o gabinete um dia antes. Como o Presidente do Senado também renunciou uma hora depois de Saá, o Presidente da Câmara, Eduardo Camaño, foi o responsável por assumir a Presidência até que a Assembléia Legislativa, convocada pela segunda vez em nove dias, designasse um novo presidente. Finalmente, em $1^{\circ}$ de janeiro de 2002, o Congresso nomeou Eduardo Duhalde. ternacional, redução drástica do déficit na contacorrente do balanço de pagamentos. Isso, por sua vez, requeria a busca flexível de preços relativos consistentes com a manutenção do poder aquisitivo e do equilíbrio externo e uma baixa taxa de inflação; 5) Competitividade da produção nacional, limitando o endividamento externo à capacidade de geração de divisas e investimentos privados diretos; 6) Incorporação generalizada e contínua da mudança tecnológica em todo o sistema econômico e social; 7) Presença de um Estado que assegure o desenvolvimento nacional, a integração social, a equidade distributiva e o bemestar (GRUPO FÉNIX, 2001).

Nesse sentido, uma das primeiras decisões de Duhalde foi promulgar a Lei de Emergência Pública $^{8}$ e Reforma do Regime Cambial (Lei n. 25 561), que deu fim à Lei de Conversibilidade. O peso foi desvalorizado, impôs-se controle aos fluxos de capitais e se "pesificou" totalmente o sistema financeiro, apesar da ampliação da vigência do corralito. Outras medidas com forte presença do Estado também foram adotadas: política de controle de preços para encorajar o consumo e evitar a inflação, aumento das taxas de exportação de commodities agrícolas e hidrocarbonetos ${ }^{9}$ e a manutenção da suspensão do pagamento da dívida externa. Dessa maneira, sob o governo Duhalde, a Argentina buscou a inserção internacional via um novo e indefinido modelo produtivo, de forte caráter pragmático e de rejeição à ortodoxia econômica.

Duhalde, em 2002, também estabeleceu o que ficou conhecido como "Mesa de Diálogo Argentino”, uma iniciativa visando à construção de consenso, da qual participavam diversos atores da

8 A Lei de Emergência permite que o poder Executivo modifique os contratos de serviços públicos privatizados, cujas tarifas eram dolarizadas, sem ingerência do Congresso. De acordo com alguns parlamentares, essa Lei implica violar o mandato do Congresso, ao ceder exageradamente atribuições ao poder Executivo.

9 Segundo Matías Longoni (2002), as retenções sobre as exportações permitiriam ao governo mais do que duplicar a receita, que passaria de US\$1,4 bilhão a mais de US\$ 3 bilhões anuais, desempenhando funções muito específicas: saldar o deficit das contas públicas, obter recursos para os programas sociais e conter a alta de alguns alimentos básicos, como óleo e pão, reduzindo seus preços internos. 
sociedade, como organizações não-governamentais (ONGs), organizações trabalhistas e empresariais, piqueteros, movimentos sociais, grupos religiosos e partidos políticos. Tal grupo conseguiu que o governo realizasse importantes políticas, muitas delas no sentido da inclusão social, como, por exemplo, os programas "Chefes e Chefas de Lares Desempregados" 10 e "Remediar"11, que foram essenciais para restabelecer a credibilidade do Estado (GRUGEL \& RIGGIROZZI, 2007).

Néstor Kirchner, eleito em 2003, manteve muitas das políticas levadas a cabo por Eduardo Duhalde em 2002. Mesmo em uma conjuntura bastante favorável, de recuperação econômica, Kirchner renovou a Lei de Emergência e renegociou alguns contratos com empresas estrangeiras que proviam os serviços públicos privatizados no governo de Carlos Menem (19891999); manteve a moeda local desvalorizada, o que favoreceu as exportações, também impulsionadas pela já mencionada alta dos preços das commodities nos mercados internacionais, principalmente a da soja e do trigo; as retenções sobre as exportações, cujas tarifas inclusive foram incrementadas, permitiram uma crescente arrecadação do governo, o que, por sua vez, permitia o superavit fiscal; a pressão inflacionária foi mantida sob controle por meio de negociação de preços com os produtores, supermercados e sindicalistas, bem como por meio de subsídios à energia ${ }^{12}$ e ao transporte. Ou seja: "estabilidade e crescimento, desde 2003 , foram uma combi-

10 O governo, por meio desse programa, oferecia 150 pesos (US\$50) a famílias desempregadas, em troca de participação em projetos como serviço comunitário, construção e manutenção de escolas, reconstrução de postos de saúde, cozinhas comunitárias, construção de casas, entre outros.

11 Tal programa organiza a distribuição de remédios básicos à população mais pobre.

12 Oficialmente, os preços dos combustíveis nas bombas dos postos de gasolina estão congelados desde 2003. Os preços de derivados de petróleo são livres, mas estão regulados por "acordos", entre as indústrias e o governo, que permitem alguns ajustes limitados. Para compensar as empresas, o governo Néstor Kirchner subsidia a diferença entre os preços internacionais e os locais. Isso foi uma tentativa de evitar que a elevação dos preços internacionais do petróleo chegasse ao mercado interno e pressionasse ainda mais a inflação. nação de uma elaboração política de bom senso e um medo generalizado das conseqüências da volta à recessão, em conjunto com uma conjuntura externa favorável” (idem, p. 16), com a preocupação principal de recompor a base industrial e os serviços públicos.

Assim, a retomada de várias funções pelo Estado foi considerada um dos principais fatores de recuperação argentina da crise econômica de 2001 e 2002. Os resultados da política econômica que privilegiou o consumo, associada às políticas sociais, foram a diminuição drástica da pobreza, do desemprego e da indigência e o aumento dos níveis de crescimento. De acordo com Gabriela Delamata (2008), a Argentina apresentou crescimento econômico na ordem de $8 \%$ a $9 \%$ anuais entre 2003 e 2007; o desemprego aberto da população economicamente ativa foi reduzido de $20,4 \%$, no primeiro trimestre de 2003 , para $8,5 \%$, no segundo trimestre de 2007; e o trabalho informal passou de $49,7 \%$ dos assalariados, no terceiro trimestre de 2003 , para $41,6 \%$, no primeiro trimestre de 2007.

Para isso, também contribuiu a conjuntura internacional. A Argentina, bem como a maior parte dos países sul-americanos, viu-se favorecida pelo aumento do preço das commodities, impulsionado principalmente pelo crescimento da China e da Índia (VADELL, 2007; LAMAS, 2008). O aumento do preço de seus produtos, juntamente com o fato de estar alijada das "novas ameaças à segurança”, depois dos ataques terroristas de 11 de setembro de 2001, constituiria um fator de aumento da margem de manobra da região no cenário internacional (VADELL, 2006; COUTINHO, 2007).

Contudo, uma política que deveria ter sido para o momento de emergência, logo depois da pior crise socioeconômica desde 1930, manteve-se no tempo praticamente sem nenhum tipo de correção de rota. A partir de 2007, a inflação passou a mostrar certo descontrole, o que acaba por minar os alcances da política de câmbio e de negociação salarial. A situação agrava-se ainda pela ingerência do Secretário de Comércio Interior, Guillermo Moreno, na medição dos índices de inflação do Instituto Nacional de Estadística y Censos (Indec). Em meados de 2008, apesar de a inflação oficial estar na casa dos $8,5 \%$ ao ano, os institutos de pesquisa privados apontavam para uma inflação de aproximadamente $25 \%$ ao ano. 
Tampouco, ao que tudo indica, houve continuidade em um aspecto que seria essencial para uma política de desenvolvimento de longo prazo, qual seja, a existência de um grupo de diálogo para discutir que tipo de políticas adotar. A "Mesa de Diálogo Argentino”, de 2002, se desintegrou assim que as políticas começaram a ter efeito e o consenso já não era mais necessário. Ademais, existem características institucionais particulares da Argentina que dificultam esse diálogo: "Nesse país não existe uma proposta articulada do governo. Pelo contrário, sua estratégia se forma sobre a conjuntura, sem um plano estratégico, descartando uma mediação institucional com setores organizados, alternando períodos de aberta confrontação com outros de relativo diálogo seletivo com certos empresários” (BOSCHI \& GAITÁN, 2008, p. 23). Os autores mencionam uma tentativa de diálogo entre setores para articular medidas referentes às estruturas macroeconômica e produtiva em 2007, ainda durante a gestão de Felisa Micelli (sucessora de Roberto Lavagna) no Ministério de Economia, sem, contudo, debater com sindicatos empresariais e atores não-empresariais ou estabelecer mecanismos de diálogo e geração de consensos.

Cristina F. de Kirchner foi eleita, em 2007, com a promessa de aprofundar o modelo realizado pelo marido até então. A nova Presidente manteve o rumo das políticas adotadas no governo anterior, sem alterar substantivamente a equipe ministerial. Uma de suas primeiras medidas, no entanto, deixou claro que não existe, na sociedade argentina, consenso sobre qual estratégia o país deve adotar para conseguir inserir-se com sucesso na economia e na política globais. A crise com os produtores agropecuários, desatada pelo estabelecimento das retenções móveis em março de 2008, foi um claro indício dessa falta de acordo. O conflito evidenciou problemáticas mais amplas do que a disputa pela renda e conflito distributivo derivado dos altos preços das commodities no mercado internacional (GODIO \& ROBLES, 2008), deixando em relevo dois projetos de país, ambos altamente sujeitos ao cenário externo para ter sucesso. Alguns setores sociais defendem a especialização do país na área em que apresenta maior vantagem comparativa, qual seja, o agronegócio. Outros setores são mais industrialistas, mas também dependem da elevação dos preços das commodities para financiar o esforço de re-industrialização da economia.
Mas, mais do que isso, o conflito trouxe à tona a fragilidade institucional da Argentina ${ }^{13}$, especialmente a centralização do poder em um reduzido número de cargos, como a Presidência, a chefia de gabinete, o Ministério de Planejamento e a Secretaria de Comércio Interior. Tais questões deverão ser tratadas e equacionadas para a Argentina poder trilhar um caminho rumo ao desenvolvimento, uma vez que os desenhos institucionais e as políticas têm grande relevância para a formação da estrutura produtiva de uma economia (LAMAS, 2008).

Contudo, durante um discurso proferido em 18 de setembro de 2008, Cristina Fernández de Kirchner deu sinais de que pretende construir um pacto social - o Acordo do Bicentenário - que dê conta de articular um projeto que contemple uma matriz produtiva diversificada, com inclusão social e com uma inserção no mundo por meio de uma política agressiva de exportações (CUFRÉ, 2008). Na mesma ocasião, diante da demanda dos industriais por uma moeda ainda mais desvalorizada $^{14}$, Cristina F. de Kirchner adotou uma postura cautelosa, afirmando que desvalorizações podem provocar inflação - o que é uma evidência da preocupação com a estabilidade dos preços, apesar dos problemas do Indec. Além disso, segundo o orçamento de 2009, apresentado ao Congresso argentino, em setembro de 2008, o governo prevê uma forte redução dos subsídios, que chega a $30 \%$ no setor energético.

Essa mudança de posição pode ser já uma reação à crise financeira dos Estados Unidos, desencadeada pela insolvência dos portadores de títulos de alto risco (subprime) derivados, especialmente, do mercado imobiliário ${ }^{15}$. A Argentina, assim como todos os países em desenvolvimen-

13 Questões relativas à distribuição de renda, à relação entre governo federal e províncias, à relação entre poderes, ao papel do Estado no que diz respeito à condução econômica, às prioridades nos gastos dos recursos arrecadados etc.

14 Os industriais defendiam a taxa de câmbio na casa dos 3,40 pesos por dólar, em lugar dos atuais 3,15 pesos por dólar.

15 “A crise das hipotecas de alto risco é um caso de bolha imobiliária nos Estados Unidos que, ao arrebentar, afetou as instituições financeiras que tinham mais quantidade de ativos respaldados no pagamento dessas hipotecas. As perdas de tais operações elevaram a dívida e reduziram o 
to, sofrerá em alguma medida seus efeitos. O preço dos bens exportáveis que geram a maior parte da receita governamental já não está tão alto. A menor rentabilidade poderá provocar uma outra mobilização dos produtores agropecuários no sentido de pressionar pela redução das retenções. Assim, a arrecadação do governo poderia ser duplamente afetada, o que dificultaria a continuidade da política atual.

A proposta governamental também inclui uma alteração estatutária do Banco de la Nación, de modo que a instituição possa financiar o governo, o que hoje não é permitido. O Ministério de Ciência e Tecnologia terá $42 \%$ mais recursos, do que em 2008, para projetos nas áreas de biotecnologia, nanotecnologia, desenvolvimento social e tecnologia da informação, o que agregaria valor a produtos argentinos. Essas seriam mudanças institucionais importantes que permitiriam uma maior imbricação público-privada.

\section{III.2. Brasil}

Ao contrário da Argentina, a recuperação da centralidade do Estado no Brasil não ocorreu em um contexto de ruptura com políticas econômicas ortodoxas. Para buscar eleger-se, tal como ocorreu com muitos governos de esquerda e centro-esquerda da América do Sul (PANIZZA, 2005), Lula teve que demonstrar publicamente que manteria orientações políticas correlatas à manutenção da estabilidade macroeconômica, haja vista a Carta ao Povo Brasileiro ${ }^{16 .}$

capital dessas instituições, limitando sua capacidade de atender às necessidades creditícias da economia. Ante essa situação, passaram a vender ativos, acentuando a queda dos preços dos ativos e, por conseguinte, suas próprias dificuldades de dívida e capital. Essa espiral descendente desatou a desconfiança entre os próprios bancos, o que produziu uma contração do crédito e propiciou as condições para a quebra de gigantes financeiros, comprometidos de maneira imprudente com operações demasiado arriscadas e com financiamento no curto prazo. Em tal momento, a intervenção do Estado se transformou em um requisito indispensável para restaurar a confiança e restabelecer a normalidade dos fluxos financeiros” (CEPAL, 2008, p. 4).

16 “Quero agora reafirmar esse compromisso histórico com o combate à inflação, mas acompanhado do crescimento, da geração de empregos e da distribuição de renda, construindo um Brasil mais solidário e fraterno, um Brasil de todos. [...] Vamos preservar o superávit primário o quanto for necessário para impedir que a dívida interna aumente e destrua a confiança na capacidade do governo de honrar os seus compromissos. Há outro caminho possível. [...]
O primeiro mandato de Lula (2003-2006) foi, então, notadamente marcado pela continuidade com relação à política macroeconômica aplicada no governo de Fernando Henrique Cardoso (19942002). Nos dois primeiros anos, frente à chamada crise de credibilidade ${ }^{17}$, o governo lançou mão de políticas monetária e fiscal altamente restritivas para alcançar metas de estabilização, combinando câmbio flutuante com livre comércio de capitais, austeros regimes de metas de inflação e de políticas fiscais, com aumento da taxa básica de juros (Selic) ${ }^{18}$, de $25 \%$ para $26,5 \%$ em três meses (DINIZ, 2005, p. 32). Desse modo, ao contrário da Argentina, que adotou medidas heterodoxas e aproveitou a conjuntura internacional para recuperar o crescimento, o Brasil demorou a acompanhar o movimento da América Latina, que, após superar consecutivas crises na região ${ }^{19}$, adentrou o período de maior crescimento sustentado desde a década de 1980, experimentando taxas superiores a 4,5\% ao ano desde 2004 (CEPAL, 2007).

Em 2002 e 2003, o Brasil obteve uma taxa de crescimento de $2,7 \%$ e $1,1 \%$, respectivamente. Em 2004, devido ao contexto internacional favorável, o PIB chegou a 5,4\%, melhor resultado desde o lançamento do Plano Real. Entretanto, dadas as políticas monetária e fiscal restritivas, o crescimento do PIB puxado pela demanda externa não se manteve e, em 2005, apesar das previsões de crescimento serem de $4,5 \%$ a $5 \%$, o país cresceu somente $3,2 \%$.

A manutenção de políticas econômicas restritivas limitou a margem de manobra para a viabilização de políticas de desenvolvimento. Mas

Vamos ordenar as contas públicas e mantê-las sob controle. Mas, acima de tudo, vamos fazer um Compromisso pela Produção, pelo emprego e por justiça social” (LULA DA SILVA, 2002).

17 Quando o Presidente assumiu, o país passava por uma crise financeira e econômica motivada por fuga de capital e agravada pela desvalorização do real - o que limitava ainda mais a margem de manobra com relação à política macroeconômica.

18 A taxa de financiamento que expressa o custo do dinheiro para empréstimos bancários com base na remuneração dos títulos públicos federais listados e negociados no Sistema Especial de Liquidação e de Custódia (Selic).

19 Em 1995, entram em crise México e Argentina; em 1998-1999, o Brasil; e, em 2001-2002, a Argentina novamente (PANIZZA, 2006). 
tal fato não significou que o governo Lula tenha ficado alheio a medidas que indicam a recuperação de capacidades estatais. Mesmo porque, se por um lado, houve a continuidade na adoção de políticas econômicas ortodoxas, por outro, a eleição de Lula em si, apoiado por uma ampla coalizão que incluía desde a esquerda tradicional até a classe média e os mais diversos setores do empresariado, significou, além de um marco no fortalecimento da democracia no país, a canalização das "aspirações por mudança nos rumos da economia e da política” (DINIZ, 2005, p. 32) dos mais diversos setores descontes com o modelo econômico vigente nos anos 1990. Sob essas condições, tem início o processo de "construção de uma nova coalizão unida pela aspiração de mudança [...] que não pode ser entendida apenas como um fenômeno de natureza conjuntural, que se explicaria simplesmente pelas crises internas e externas do momento, ou pela estrutura de marketing utilizada na campanha eleitoral” (idem, p. 10).

Logo após a posse, preocupado em estabelecer articulação com a sociedade, Lula anunciou a criação do Conselho Nacional de Desenvolvimento Econômico e Social (CDES), órgão consultivo ligado à Presidência da República, exatamente com o objetivo de definir um projeto de longo prazo de desenvolvimento para o país por meio do diálogo social, institucionalizando a negociação entre o Estado e a sociedade organizada - trabalhadores, empresários, movimentos sociais e personalidades expressivas de outros setores, como, por exemplo, o acadêmico - em uma área até então impensável. A metodologia de trabalho inclui uma agenda que, apesar de ser pautada pelo governo, por meio da Secretaria de Desenvolvimento Econômico e Social (Sedes), envolve um amplo leque temático que vai desde reformas estruturais como a política e a tributária - até a discussão de soluções para a crescente desigualdade social do país $^{20}$. Segundo recente estudo sobre o primeiro ano de funcionamento do CDES, já seria possível identificar um processo de negociação ${ }^{21}$ em que

20 Como aponta Costa (2006; 2008), o grande desafio da construção de um pacto de cooperação seria o enfrentamento da questão da retomada do crescimento em conjunto com a redução das desigualdades sociais.

21 Costa identifica essa tendência ao estudar o processo de criação das seis cartas de concertação que delimitam as bases sobre as quais o CDES atuaria. Conforme a quinta interesses diferentes e antagônicos estariam gerando um movimento de agregação de elites em torno de um projeto para o país22: "O Conselho produziu resultados e mudanças significativas, ainda que de alcance limitado. Entre os resultados, destaco a definição de uma agenda pactuada de desenvolvimento econômico e social cuja importância está no fato de ter conjugado intencionalmente crescimento econômico com desenvolvimento social” (COSTA, 2008, p. 141).

Aliás, quando o presidente Lula reelegeu-se, em 2006, entre os principais temas da agenda estava a dificuldade de promover o desenvolvimento por meio da retomada do crescimento do país. Como argumentamos, o país demonstrou pífios resultados no acréscimo do PIB, mesmo frente à conjuntura internacional favorável, considerado aquém das possibilidades do país. Foi nesse contexto que, com vistas a superar umas das maiores dificuldades da economia brasileira das últimas décadas e a garantir a continuidade do crescimento em longo prazo, por meio de processos de expansão dos investimentos sustentados, logo após sua reeleição, em janeiro de 2007, o Presidente Lula anunciou novas medidas para atingir a meta de conduzir o crescimento da economia brasileira a $4,5 \%$ ao ano, em 2007, e 5\%, a partir de 2008 . O Programa de Aceleração do Crescimento (PAC) foi apresentado como um "pacote" de medidas com vistas a incentivar o investimento em áreas consideradas estratégicas.

O programa previa mesclar elementos da antiga agenda das reformas liberalizantes com o in-

delas: "No novo contrato social a ser negociado, o sistema financeiro deve ser aperfeiçoado [...] canalizando para as atividades produtivas e as políticas sociais uma proporção maior das poupanças do país [...] e [a nova contratualidade] deve refletir este amplo acordo social e político, em torno das questões essenciais para o futuro do Brasil, sem cuja solução não haverá futuro, nem para a classe dos miseráveis [...] nem para os bem situados de hoje" (COSTA, 2008, p. 150-151).

22 Se, por um lado, o CDES pode ser interpretado como uma importante iniciativa, que validaria a tendência identificada por Diniz (2005), de construção de uma nova coalizão sustentadora de um novo modelo de desenvolvimento pós-reformas estruturais, por outro lado, cabe a advertência para a possibilidade de subutilização da arena dessa interlocução. Fleury (2005), ex-conselheira do CDES, chama a atenção justamente para isso, apontando uma tendência da instância ser usada como "palco" do governo para a apresentação de políticas. 
cremento do investimento, por meio de incentivos públicos diretos e indiretos ${ }^{23}$ (como afirma o próprio programa, por meio de uma "ação firme do governo federal”). Estruturado com base em cinco pontos principais - investimento em infraestrutura, estímulo ao crédito e ao financiamento, melhora do ambiente de investimento, desoneração e aperfeiçoamento do sistema tributário e, finalmente, medidas fiscais de longo prazo -, o PAC estipulava investimentos de mais de R $\$ 500$ bilhões nas áreas de logística, energia e infra-estrutura urbana ${ }^{24}$, entre os anos de 2007-2010.

A expectativa do governo é de que a expansão do investimento público ${ }^{25}$ nas três grandes áreas gere o aumento do investimento privado. A idéia é integrar o aumento do investimento público com políticas capazes de promover incentivos tributários e financeiros ao setor privado, principalmente por meio de estímulos fiscais a setores e bens específicos e da expansão e redução do custo do crédito para investimento. Tais políticas deveriam ser subsidiadas por rearranjos institucionais que incentivassem o investimento privado na indústria e na infra-estrutura e, assim, tornassem consistente o crescimento do país, com manutenção da estabilidade macroeconômica.

Nota-se, portanto, que o carro-chefe do segundo mandato de Lula assenta-se sobre diretrizes que, de um lado, claramente promovem o resgate do papel do Estado, principalmente por meio da recuperação de investimentos públicos, e, por

23 O investimento privado dar-se-ia por meio da remoção de obstáculos burocráticos, administrativos, normativos, jurídicos e legislativos ao crescimento (BRASIL. Ministério da Fazenda, 2007).

24 De acordo com dados do Banco Nacional de Desenvolvimento Econômico e Social (BRASIL. Banco Nacional de Desenvolvimento Econômico e Social, 2007), tal aporte de recursos significaria um aumento real de 362\% nos investimentos em geração de energia elétrica, de $215 \%$ em habitação, de $110 \%$ em transmissão de energia, de $145 \%$ em saneamento e de $80 \%$ em petróleo e gás.

25 Os recursos públicos dirigidos às áreas de logística, infra-estrutura urbana e energia chegariam a R\$ 287 bilhões. As estatais ficariam responsáveis por investir R\$ 219,20 bilhões. O aporte de recursos do orçamento fiscal seria proporcionalmente menor, o equivalente a $\mathrm{R} \$ 67,80$ bilhões, $13,5 \%$ do total previsto. Os investimentos da iniciativa privada ficariam em R\$ 216,9 bilhões. O investimento público seria responsável por $75 \%$ do total do valor previsto para logística, o que equivaleria a R\$ 43,6 bilhões (RIBEIRO, 2008). outro, preservam antigas preocupações referentes à manutenção da estabilidade e de um ambiente institucional favorável para os investidores. Demonstrando essa orientação, o discurso do Presidente Lula durante o lançamento atrelou a viabilidade do PAC à manutenção de políticas macroeconômicas ortodoxas. O Presidente destacou que o programa estaria vinculado à disciplina fiscal e monetária e que a estabilidade econômica não estaria em risco. Na mesma ocasião, o Ministro da Fazenda, Guido Mantega, reafirmou o compromisso com o controle da inflação, apontando que o estímulo à atividade econômica não geraria aumento nos preços. Esse ponto, aliás, segue como o mais controverso dentro do governo: frente às recomendações do CDES de flexibilização da política macroeconômica ortodo$\mathrm{xa}$, o posicionamento do governo foi de que as diretrizes quanto a esse matéria não devem mudar (VIZEU \& BIN, 2008).

Ainda não é possível apontar o alcance de tais medidas. Podem-se notar, contudo, fortes indícios da retomada do papel do Estado na economia e de construção de base institucional para o estabelecimento de imbricação público-privada. Um indício desse movimento seria o fortalecimento do Banco Nacional de Desenvolvimento Econômico e Social (BNDES), com resgate de seu papel central na viabilização do incremento de investimento na economia, que havia se arrefecido na década de 1990. Nos primeiros quatro meses de 2008, o volume de desembolsos aumentou $77 \%$ em relação a igual período de 2007. A expectativa é de que o BNDES continue desempenhando um papel importante na sustentação das taxas de investimento e no estímulo às políticas de desenvolvimento de uma maneira geral ${ }^{26}$. Segundo o Presidente do banco, Luciano Coutinho, o BNDES tem liquidez necessária para manter os ritmos de investimentos, mesmo frente à crise dos Estados Unidos, uma vez que a disponibilidade de recursos, em 2008 e para boa parte de 2009, já estaria equacionada (LAMUCCI, 2008).

26 Previu-se, no lançamento do PAC, que o banco contasse com R\$ 210 bilhões para empréstimos até 2010, com a redução do spread de 1,4\% para $1,1 \%$ nas linhas de financiamento, e de $1,5 \%$ para $0,9 \%$ na compra de máquinas e equipamentos. Entre fevereiro de 2007 e janeiro de 2008, os empréstimos cresceram $19 \%$ e significaram um aumento de $62 \%$, em relação ao período anterior, para empréstimos para a área de infra-estrutura (idem). 
Outro passo relevante que aponta para a viabilização de uma imbricação público-privada que possa dar suporte ao desenvolvimento foi o Programa de Desenvolvimento Produtivo (PDP), lançado em maio de 2008 e apontado como a nova política industrial do governo. O PDP prevê a ampliação da formação bruta de capital fixo, a manutenção do equilíbrio no balanço de pagamentos, a elevação na capacidade de inovação e o fortalecimento das pequenas e médias empresas por meio de instrumentos como o incentivo fiscal e de crédito, compras governamentais, regulação técnica, sanitária, econômica e concorrencial e apoio técnico 27 . O impacto da PDP sobre a viabilização do desenvolvimento ainda é desconhecido, mas é possível dizer que se tratou de um passo importante com relação à sua antecessora, a Política Industrial, Tecnológica e de Comércio Exterior (PITCE) ${ }^{28}$, uma vez que estabeleceu metas e diretrizes mais específicas ${ }^{29}$. Em 2004, quando foi lançada a PITCE, foram estabelecidos eixos prioritários para direcionar as políticas governamentais, com o objetivo de fortalecer e expandir a base industrial brasileira por meio da melhoria da capacidade inovadora das empresas ${ }^{30}$. Entretanto, apesar de a PITCE centralizar e

27 As metas a serem alcançadas até 2010 dizem respeito à ampliação do investimento fixo de 17,6\% do PIB em 2005 para $21 \%$, à elevação do gasto privado em pesquisa e desenvolvimento de $0,51 \%$ do PIB em 2005 para $0,65 \%$, à ampliação da participação brasileira nas exportações mundiais de 1,18\% em 2007 para 1,25\%, e ao aumento do número de micro e pequenas empresas exportadoras de 11.792 em 2006 para 12.971 (OBSERVATÓRIO POLÍTICO SUL-AMERICANO, 2008).

28 Ver Brasil. Agência Brasileira de Desenvolvimento Industrial (2009).

29 Entre as medidas de desoneração tributária, que são da ordem de R\$21,4 bilhões até 2011, estão a extinção do Imposto sobre Operações Financeiras (IOF) nas operações de crédito do BNDES, da Financiadora de Estudos e Projetos do Ministério da Ciência e Tecnologia (Finep) e da Agência Especial de Financiamento Industrial do BNDES (Finame); a isenção de Contribuição para o Programa de Integração Social (PIS) e de Contribuição para o Financiamento da Seguridade Social (Cofins) na compra de bens de capital para empresas que destinem ao menos $60 \%$ da produção à exportação; a redução de até $13,1 \%$ da contribuição que as empresas exportadoras de tecnologia da informação fazem ao Instituto Nacional do Seguro Social (INSS) com base na folha de pagamentos. (OBSERVATÓRIO POLÍTICO SUL-AMERICANO, 2008).

30 Com base na diretriz central de promoção da inovação e da agregação de valor aos processos, produtos e serviços aprofundar medidas de políticas já existentes no governo anterior (SANTANA, 2005), seu alcance foi limitado, haja vista a ausência de metas específicas para o incentivo à industrialização e à promoção de pesquisas nas áreas prioritárias.

A novidade dessas decisões reside justamente na proposta de coordenar políticas usualmente dispersas na agenda governamental. Ao buscar transformar diretrizes e diagnósticos, presentes em políticas e programas anteriores, em ações coordenadas, as políticas implementadas estariam abrindo espaço para a construção de uma nova dinâmica público-privada, na qual as políticas estatais estabeleceriam estruturas institucionais capazes de se impor de maneira seletiva às forças do mercado. Tal movimento seria consubstanciado por instituições que atuam, viabilizam e/ou coadunam com essas políticas, como é o caso do BNDES e do CDES. Entretanto, ainda, é cedo para dizer se tais mecanismos persistirão no tempo e se serão capazes de contribuir para o crescimento sustentado do país.

\section{CONSIDERAÇÕES FINAIS: LIMITES E POSSIBILIDADES PARAA INTEGRAÇÃO}

Como afirma Hurrel, as teorias da convergência pretendem compreender a dinâmica da cooperação regional e a integração político-ideológica entre os Estados que conformam a região. Assim, como expressa o autor, "o ressurgimento do impulso integracionista em meados da década de 1980 pode ser visto como resultado da convergência das preferências de políticas econômicas nacionais, centradas em torno da liberalização econômica e da desregulamentação" (HURRELL, 1995, p. 49). Essa convergência dar-se-ia também no plano ideológico, que estimularia os Estados a uma coordenação de políticas no âmbito regional.

De fato, a assinatura do tratado de Assunção, em 1991, por parte dos presidentes Fernando Collor de Mello, do Brasil, Carlos Menem, da Argentina, Luis Alberto Lacalle, do Uruguai e Andrés Rodríguez, do Paraguai, que deu origem ao Mer-

da indústria nacional, foram estabelecidos três eixos de atuação na PITCE: linhas de ação horizontais referentes à inovação e ao desenvolvimento tecnológico, à inserção externa e exportações, à modernização industrial e ao ambiente institucional; setores estratégicos, delimitados em software, semicondutores, bens de capital, fármacos e medicamentos; e em atividades portadoras de futuro, como biotecnologia, nanotecnologia e energias renováveis (BRASIL, 2008). 
cado Comum do Sul (Mercosul), enquadra-se nesse contexto de hegemonia neoliberal, o que facilitou o pontapé inicial para o projeto de integração. Valorizavam-se a abertura de mercados e a globalização financeira e produtiva, em oposição ao modelo de integração das décadas de 1950 e 1960, cujo ponto de referência era o de aumentar as vantagens de substituir importações com um critério sub-regional, em contraste com a opção de substituí-las com um critério nacional. Ao contrário, o regionalismo aberto da década de 1990 apresentou-se como uma postura reativa e defensiva, por meio da qual os Estados buscavam ser mais competitivos, ao mesmo tempo em que reduziam a capacidade estatal de formular políticas e regular os mercados individualmente (LIMA \& COUTINHO, 2005).

O início do século XXI inaugurou, por sua vez, uma nova fase de convergência, com o resgate do papel do Estado na condução das políticas para o desenvolvimento, o que foi imprescindível para recuperação da economia e para a retomada do crescimento da Argentina e do Brasil no período pós-crise. Como já mencionado, essa retomada do Estado não implicou, no entanto, um descuido em relação a questões centrais para a ortodoxia, como disciplina fiscal e estabilidade, principalmente no caso do governo Lula da Silva. Pelo contrário, esse tipo de tema ocupa um lugar privilegiado no rol de preocupações de vários dos governos progressistas do século XXI, na região, o que os diferencia substancialmente do desenvolvimentismo da década de 1960.

Contudo, ainda que a convergência política dos países em torno da abertura comercial e financeira possa ser um elemento que facilite o processo de integração regional (e, depois, em termos do retorno do Estado como elemento essencial para o desenvolvimento) ela não é suficiente para compreender essa dinâmica de avanços, impasses e retrocessos na relação Argentina-Brasil.

Uma análise um pouco mais sistemática nos permite perceber que a Argentina e o Brasil têm feito escolhas distintas no que diz respeito ao tipo de política adotada. O Brasil tem recorrido a práticas mais ortodoxas, como políticas monetárias restritivas para conter as expectativas de inflação, enquanto a Argentina tem preferido medidas heterodoxas, como controle de preços e restrição às exportações, bem como outras políticas de incentivo ao consumo. Em certa medida, a diferença entre as escolhas pode ser atribuída à própria trajetória econômica e política de ambos os países. As reformas pró-mercado foram mais intensas na Argentina do que no Brasil, o que implicou, no que diz respeito à estrutura produtiva, por exemplo, uma maior desindustrialização e a extinção de algumas instituições desenvolvimentistas, como o Banco Nacional de Desarrollo. O governo de Carlos Menem (1989-1999) ainda tentou criar o Banco de Integración y Comércio Exterior (BICE), que ainda existe, mas não tem um papel relevante na economia, ao contrário de seu equivalente brasileiro, o BNDES. Ademais, a crise socioeconômica argentina foi bem mais grave do que a crise brasileira de 1998/1999. Além de economicamente quebrado, o país foi testemunha de manifestações sociais, saques e atos de vandalismo, que extrapolaram o âmbito econômico e contaminaram também o campo político-institucional, sendo que as políticas econômicas da década de 1990 foram fortemente identificadas, na população, como as provocadoras da maior crise econômica desde 1930. Tal associação não é feita no Brasil em relação à crise de 1999, talvez porque os efeitos não tenham sido tão graves quanto no país vizinho. Isso faz com que, no imaginário popular, a rejeição às políticas pró-mercado seja maior na Argentina do que em outros países - o que tem sido amplamente explorado pelo casal Kirchner.

O fato é que, na Argentina, por causa da crise e de um contexto internacional favorável (VADELL, 2006), houve uma maior autonomia do governo para realizar políticas macroeconômicas, mas isso se deu em conjunto com evidentes signos de debilidade institucional, no decorrer das últimas décadas. No Brasil, ao contrário, a reduzida autonomia com relação à política macroeconômica veio acompanhada da manutenção de instituições que se têm provado importantes instrumentos de desenvolvimento, como o BNDES, além de outras instituições que promovem o diálogo visando à construção de um consenso sobre um projeto de país.

Assim, as diferenças cruciais entre os dois países seriam a discrepância no que se refere à consolidação de um aparato institucional que conduzisse ao crescimento e os diferentes níveis de construção de bases de consenso sobre o direcionamento para a realização de políticas que recuperam o papel do Estado na condução do desenvolvimento. Nesse sentido, apesar da retomada da centralidade do Estado na condução de po- 
líticas para o desenvolvimento ser perceptível em ambos os países, é possível notar várias diferenças que dificultam a construção de um modelo de desenvolvimento comum para a região.

Em longo prazo, a diferença das escolhas reflete-se na estrutura produtiva de cada país, o que, por sua vez, tem efeitos sobre os interesses que o governo será pressionado a defender em âmbito externo. Isto é, a posição de um país em uma negociação internacional (ou multilateral) dependerá não só dos constrangimentos impostos pelas relações de poder com os demais países, mas também dos interesses domésticos, das alianças de setores e classes em um "jogo de dois níveis" (PUTNAM, 1988). Nesse sentido, políticas de incentivo ao desenvolvimento muito diferentes podem resultar em uma estrutura sócio-produtiva tão distinta que poderia inviabilizar qualquer convergência de interesses na arena internacional. A questão então é: como o Mercosul, que se pretende uma união aduaneira, hoje imperfeita, vai lidar com esse desafio que se vislumbra para o futuro? A tendência não parece se apresentar de maneira unívoca, isto é, rumo a uma integração ou a uma desintegração do Mercosul, e sim de maneira truncada, com idas e vindas, dependente da diplomacia presidencial e da situação periférica do bloco no atual cenário geopolítico global.

O desafio da integração por parte do Brasil e da Argentina tem sua expressão mais notória em algumas políticas de aproximação-distanciamento ao longo do ano de 2008, que evidenciam uma constante no relacionamento entre ambos os países. Essas políticas de aproximação-distanciamento entre Argentina e Brasil apresentam-se como:

\section{IV.1. Distanciamento em órgãos multilaterais}

O distanciamento e a falta de coordenação de posições mostrou-se evidente na rodada de Doha para a liberalização do comércio da Organização Mundial do Comércio (OMC), em que o Brasil aceitou a proposta apresentada pelo Diretor-Geral da organização, Pascal Lamy, que previa medidas para a liberalização de produtos agrícolas e nãoagrícolas ${ }^{31}$. A aceitação da proposta pelo governo brasileiro gerou críticas dos demais membros do G-20, que se manifestaram contra o pacote de soluções de Lamy, o que também teria criado ten-

31 No que se refere à agricultura, a proposta sugeria uma redução dos subsídios distorcivos nos Estados Unidos, em sões no Mercosul, segundo o negociador argentino, Alfredo Chiaradia (LANDIM \& ROCHA, 2008). A Argentina considerou que a proteção a setores industriais sensíveis deveria estender-se a um número maior de linhas tarifárias do que a aceita pelo Brasil.

Em grande parte, essa divergência de posições deveu-se exatamente ao fato de Argentina e Brasil possuírem estruturas produtivas divergentes: nas palavras do Assessor para Assuntos Internacionais do Presidente Lula, Marco Aurélio Garcia, na rodada de Doha, os países defenderam individualmente seus interesses, deixando de lado os interesses do bloco (CARMO, 2008).

\section{IV.2. Aproximação nas relações bilaterais}

Como já se mencionou, a integração regional é uma das prioridades do governo Lula e dos governos Néstor Kirchner (2003-2007) e Cristina F. de Kirchner, uma vez que é vista como necessária para a expansão do capitalismo brasileiro e argentino. Nesse sentido, as disparidades de posições em Doha não significaram o abandono da agenda de integração pelos países, como é possível observar nos dois encontros entre Lula e Cristina realizados após a divergência na rodada de negociação.

No início de agosto de 2008, imediatamente depois do fracasso de Doha, o Presidente Lula visitou a Argentina acompanhado por mais de 260 empresários brasileiros e prometeu mais investi-

70\%, e na União Européia, em 80\%. Dessa forma, os EUA deveriam diminuir o teto anual de subsídios de US\$ 48 bilhões para US\$ 14,4 bilhões e a União Européia deveria limitá-los a um máximo de US\$ 22 bilhões. Lamy sugeria também para os países desenvolvidos uma redução de 70\% nas tarifas de importação que estivessem acima do nível de $75 \%$ sobre o valor do produto. A proposta permitia que esses países indicassem $4 \%$ de suas linhas tarifárias como sensíveis, e sujeitas, portanto, a cortes menores. Os países em desenvolvimento, por sua vez, teriam a flexibilidade para designar $12 \%$ de suas linhas tarifárias agrícolas como especiais, devido a questões de segurança alimentar e subsistência, as quais estariam isentas de cortes. Com relação aos bens não-agrícolas, a proposta previa níveis tarifários entre $20 \%$ e $25 \%$ para os países em desenvolvimento, dependendo da fórmula que escolhessem. Os países que optassem pela redução média de $25 \%$ poderiam excluir $14 \%$ de suas linhas tarifárias, sobre as quais a redução seria menor; ao passo que os países que optassem por uma diminuição média de $20 \%$ não poderiam indicar exceções (OBSERVATÓRIO POLÍTICO SUL-AMERICANO, 2008). 
mentos no país vizinho. Na ocasião, apesar de não terem assinado acordos, os presidentes trataram de medidas visando a aumentar o vínculo estratégico produtivo, com a criação de um fundo soberano para o financiamento de investimentos de empresas brasileiras na Argentina e para a associação de empresas de ambos os países ${ }^{32}$.

No mês seguinte, foi a vez de Cristina Fernández de Kirchner vir ao Brasil. Os presidentes assinaram o Convênio do Sistema de Pagamentos em Moeda Local ${ }^{33}$, que permite que as transações comerciais entre os dois países não necessitem mais da intermediação do dólar. Além disso, Lula e Cristina firmaram um convênio de cooperação entre o BNDES e o BICE, que prevê o financiamento conjunto de empreendimentos produtivos, principalmente a pequenas e médias empresas nos dois países. Na ocasião, o Brasil ainda fez um convite para que a Argentina participe da construção da infra-estrutura necessária à exploração do petróleo brasileiro na camada pré$\mathrm{sal}^{34}$.

É possível notar claramente, a despeito de escolhas díspares e das diferenças com relação às estruturas produtivas, um esforço dos dois governos no sentido de dar continuidade à cooperação bilateral, com medidas que, se levadas a cabo, podem capacitar os dois países a trilhar o caminho do desenvolvimento regional. Tal fato abriria espaço para imaginarmos o aprofundamento da integração via construção de um modelo de desenvolvimento próprio.
IV.3. O “duplo movimento" como respostas nacionais ou movimento coordenado

Um terceiro elemento que devemos considerar são as políticas de resposta ao fracasso do desenvolvimento neoliberal. O "duplo movimento" configura-se a partir da ação estatal frente ao perigo da ruptura do tecido social. A forma mais comum de resposta são as tendências nacionalistas na área do desenvolvimento econômico. Que conseqüência teria esse processo para a integração regional sem a devida coordenação política dos principais membros do Mercosul?

Nesse caso, as perspectivas em torno das convergências sóciopolíticas entre o Brasil e a Argentina só conseguem interpretar os momentos de aproximação, deixando um vácuo explicativo nas situações conflitivas entre os atores. A importância dos regionalismos como tendência sistêmica e, portanto, das potências regionais e seu papel de liderança, junto com o retorno do Estado na cena econômica doméstica, como indutor das políticas de desenvolvimento, deveriam agir como fortes incentivos para redesenhar a coordenação estratégica entre o Brasil e a Argentina, visado a um aprofundamento no processo de integração.

Essas transformações na relação Estado-mercado estão hoje em discussão no plano global depois da crise financeira internacional de 2007-2008. O impacto da crise do projeto da globalização, que atingiu o Primeiro Mundo, será mais um desafio no processo de integração regional do Mercosul.

Javier Vadell (javier.vadell@pucminas.br) é Doutor em Ciências Sociais pela Universidade Estadual de Campinas (Unicamp) e Professor da Pontifícia Universidade Católica de Minas Gerais (PUC-MG).

Bárbara Lamas (lamas.barbara@gmail.com) é Doutoranda pelo Instituto Universitário de Pesquisas do Rio de Janeiro (Iuperj).

Daniela M. de F. Ribeiro (dribeiro@iuperj.br) é Doutoranda pelo Instituto Universitário de Pesquisas do Rio de Janeiro (Iuperj).

32 O objetivo desse encontro, ao que se somou Hugo Chávez, foi aprofundar a integração em matéria econômica e comercial e ampliar os investimentos recíprocos. A Presidente Cristina Kirchner expressou nessa oportunidade: “es inédita la presencia de tantos empresarios en nuestro país” (SEITZ, 2008).

33 O sistema de pagamentos em moeda local, criado no âmbito do Mercosul, em junho de 2007, tornou facultativa aos países membros a utilização de moedas locais no comércio exterior. De acordo com a decisão, a efetivação do SML deveria ser regulada por acordos bilaterais entre os bancos centrais dos países. O cronograma entre Brasil e Argentina para a operacionalização do sistema foi adotado em fevereiro de 2008, na primeira reunião ocorrida no âmbito do Mecanismo de Integração e Coordenação BrasilArgentina. O sistema de pagamentos em moeda local deverá entrar em funcionamento a partir do dia 03 de outubro. A próxima reunião presidencial deve ocorrer no dia 23 de abril de 2009.

34 Segundo o Ministro de Minas e Energia do Brasil, a parceria poderia ocorrer seguindo os modelos atuais de concessão ou por meio de um processo de terceirização e prestação de serviços (LYRA, 2008). 


\section{REFERÊNCIAS BIBLIOGRÁFICAS}

BOSCHI, R. \& GAITÁN, F. 2008. Gobiernos Progresistas, Agendas Neodesarrollistas y Capacidades Estatales : La Experiencia Reciente en Argentina, Brasil y Chile. In : LIMA, M. R. S. D. Desempenho de governos progressistas no Cone Sul : agendas alternativas ao neoliberalismo. Rio de Janeiro : Iuperj.

CARMO, M. 2008. Após Doha, Mercosul buscará negociações '4 mais 1', diz Marco Aurélio. BBC Brasil, São Paulo, 3.ago. Disponível em http://www.bbc.co.uk/portuguese/reporterbbc/story/2008/08/080803_argentinareuniao_mc_ac.shtml. Acesso em : 4.ago.2008.

COSTA, V. 2006. Os Conselhos do CDES : experimento sem conclusão. Insight Inteligência, v. 6 , n. 32, p. 146-161.

2008. CDES : O aprendizado do pacto. Insight Inteligência, v. 10, n. 41, p. 138-155.

COUTINHO, M. 2007. Novos ventos do Sul : um breve ensaio de economia política contemporânea. Análise de Conjuntura OPSA, Rio de Janeiro, n. 1, jan., p. 2-12. Disponível em : http://observatorio.iuperj.br/pdfs/26_analises_Novos_ventos_do_sul.pdf. Acesso em : 10.abr.2009.

CUFRÉ, D. 2008. "Hay que mirar el dólar y la inflación”. Página /12, Buenos Aires, 19.set. Disponível em : http://www.pagina12.com.ar. Acesso em : 19.set.2008.

DELAMATA, G. 2008. Luchas sociales, gobierno y Estado durante la presidencia de Néstor Kirchner. Análise de Conjuntura OPSA, Rio de Janeiro, n. 2, fev. Disponível em : http:// observatorio.iuperj.br/pdfs/42_analises_AC_n_2_fev_2008.pdf. Acesso em : 10.abr.2009.

DINIZ, E. 2005. Empresário, Estado e Democracia : continuidade e mudança entre os governos Fernando Henrique e Lula. In : La esperanza venció el miedo? Uma evaluación de los primeros años del gobierno Lula en Brasil, Universidad de Salamanca. Disponível em : http://neic.iuperj.br/artigos.html. Acesso em : 10.abr.2009.
EVANS, P. 1996. El Estado como problema y como solución. Desarrollo Económico, Buenos Aires, v. 35, n. 140, p. 595-628, jan.-mar.

1997. The eclipse of the State? Reflections on stateness in an era of globalization. World Politics, Cambridge, v. 50, n. 1. p. 62-87, Oct.

FERRARI, A. \& CUNHA, A. M. 2005. As origens da crise argentina : uma sugestão de interpretação. In : XXXIII Encontro Nacional de Economia, Natal. Disponível em : http:// www.anpec.org.br/encontro2005/artigos/ A05A023.pdf. Acesso em : 10.abr.2009.

FILGUEIRAS, L. 2002. Neoliberalismo e crise na América Latina : O caso do Brasil. Disponível em : http://bibliotecavirtual.clacso.org.ar/ ar/libros/osal/filgueiras.doc. Acesso em 10.abr.2009.

FLEURY, S. 2005. O Conselho de Desenvolvimento Econômico e Social do Governo Lula. Disponível em : http://www.cdes.gov.br/exec/ notainformativa/exibe_nota_informativa. Acesso em : 10.abr.2009.

GODIO, J. \& ROBLES, A. J. 2008. El Tiempo de CFK. Buenos Aires : Corregidor.

GRUGEL, J. \& RIGGIROZZI, M. P. 2007. The return of the state in Argentina. International Affairs, London, v. 83, n. 1. p. 87-107.

GRUPO FÉNIX. 2001. Plan Fénix : Propuestas para el desarrollo con equidad. Enoikos, Buenos Aires, n. 20. Disponível em : http:// www.econ.uba.ar/planfenix/index2.htm. Acesso : 10.abr.2009.

HURRELL, A. 1995. O ressurgimento do regionalismo na política mundial. Contexto Internacional, Rio de Janeiro, v. 17, n. 1. p. 23-59, jan-jun.

LAMAS, B. 2008. A disputa com os ruralistas: retenções e política de desenvolvimento na Argentina. Observador On-Line, Rio de Janeiro, v. 3, n. 8, p. 2-18. Disponível em : http:// observatorio.iuperj.br/pdf s / 42_observador_topico_Observador_v_3_n_8.pdf. Acesso em : 10.abr.2009. 
LAMUCCI, S. 2008. BNDES tem recursos suficientes, diz Coutinho. Valor Econômico, São Paulo, 24.set. Disponível em : http:// www.valoronline.com.br/ValorImpresso/ MateriaImpresso.aspx?dtMateria $=24 / 9$ / 2008\%200:00:00\&codMateria=5166212\&cod Categoria=89. Acesso em : 24.set.2008.

LANDIM, R. \& ROCHA, J. 2008. Empresários têm prioridades distintas para acordos bilaterais. Valor Econômico, São Paulo, 30.jul.

LIMA, M. R. S. D. \& COUTINHO, M. 2005. Globalização, Regionalização e América do Sul. Análise de Conjuntura OPSA, Rio de Janeiro, n. 6. Disponível em : http://observatorio.iuperj.br/artigos_resenhas/ Globalizacao,\%20Regionalizacao\%20e\% 20Am\%C3\%A9rica\%20do\%20Sul.pdf. Acesso em : 10.abr.2009.

2006. Integração Moderna. Análise de Conjuntura OPSA, Rio de Janeiro, n. 1, jan. Disponível em : http://observatorio.iuperj.br/ pdfs/14_analises_integracao_moderna.pdf. Acesso em : 10.abr.2009.

2007. Uma versão estrutural do regionalismo. In : DINIZ, E. Globalização, Estado e desenvolvimento. Rio de Janeiro : FGV.

LONGONI, M. 2002. Retenciones : serían del $20 \%$ sólo para granos, aceites y harinas. Clarín, Buenos Aires, 4.abr. Disponível em : http:// www.clarin.com/diario/2002/04/04/e02001.htm. Acesso em : 3.nov.2008.

LULA DA SILVA, L. I. 2002. Carta ao povo brasileiro. Disponível em : http://www.iisg.nl/ collections/carta_ao_povo_brasileiro.pdf. Acesso em : 10.abr.2009.

LYRA, P. D. T. 2008. Lula convida argentinos a investirem no pré-sal. Valor Econômico, São Paulo, 9.set. Disponível em : http:// www.valoronline.com.br/ValorImpresso/ MateriaImpresso.aspx?dtmateria $=9 / 9 /$ 2008\&codmateria $=5140340 \&$ codcategoria $=89$. Acesso em : 9.set.2008.

PANIZZA, F. 2005. Unarmed Utopia Revisited : the Resurgence of Left-of-Centre Politics in Latin America. Political Studies, Sheffield,v. 53, n. 4, p. 716-734.
2006. La Marea Rosa. Análise de Conjuntura OPSA, Rio de Janeiro, n. 8, ago. Disponível em : http://observatorio.iuperj.br/pdfs/ 21_analises_La_marea_rosa.pdf. Acesso em : 10.abr.2009.

POLANYI, K. 2000. A Grande Transformação : as origens de nossa época. Rio de Janeiro : Campus.

PUTNAM, R. 1988. Diplomacy and domestic politics: the logic of two-level games. International Organization, Cambridge, v. 42, n. $3,427-460$

RIBEIRO, D. 2008. Programa de Aceleração do Crescimento : marco na agenda pós-reformas liberalizantes? Observador On-Line, v. 3, n. 6, p. 2-25, jun. Disponível em : http:// observatorio.iuperj.br/pdfs/ 40_observador_topico_Observador_v_3_n_6.pdf. Acesso em 10.abr.2009.

SANTANA, C. H. 2005. Política Industrial do Governo Lula. Limites da mudança. Rio de Janeiro. Dissertação (Mestrado em Ciência Política). Instituto Universitário do Rio de Janeiro.

SEITZ, M. 2008. Lula y Chávez visitan Argentina. BBC Mundo.com, 04.ago. Disponível em : http://news.bbc.co.uk/go/pr/fr/-/hi/spanish/ latin_america/newsid_7539000/7539716.stm. Acesso em : 10.abr.2009.

VADELL, J. 2006. A Política Internacional, a Conjuntura Econômica e a Argentina de Néstor Kirchner. Revista Brasileira de Política Internacional, Brasília, v. 49, n. 1, p. 194-204, jan.jun.

2007. As implicações políticas da relação China-América do Sul no século XXI. Cena Internacional, Brasília, v. 9, n. 2, p. 194-214.

VIZEU，F. \& BIN，D. 2008. Democracia deliberativa : leitura crítica do caso CDES à luz da teoria do discurso. Revista de Administração Pública, Rio de Janeiro, v. 42, n. 1. p. 83-108. 


\section{OUTRAS FONTES}

BRASIL. 2008. Programa de Aceleração do Crescimento. Balanço do Programa de Aceleração do Crescimento. Disponível em : http:// www.brasil.gov.br/pac/balancos. Acesso em : 10.abr.2009.

BRASIL. Agência Brasileira de Desenvolvimento Industrial. 2009. Política Industrial, Tecnológica e de Comércio Exterior. Disponível em : http://www.abdi.com.br/?q=node/77. Acesso em : 10.abr.2009.

BRASIL. Banco Nacional de Desenvolvimento Econômico e Social. 2007. Porque o PAC vai aumentar o investimento? Visão do Desenvolvimento, Brasília, n. 24, fev. Disponível em : http://www.bndes.gov.br/conhecimento/visao/ visao_24.pdf. Acesso em : 10.abr.2009.

BRASIL. Ministério da Fazenda. 2007. Programa de Aceleração do Crescimento : PAC 20072010, editado pelo Ministério da Fazenda. Dis- ponível em : http://www.fazenda.gov.br/ portugues/releases/2007/r220107-PAC.pdf. Acesso em : 18.jun.2008.

CEPAL. 2007. Estudio económico de América Latina y el Caribe 2006-2007. CEPAL. Disponível em : http://www.eclac.org/cgi-bin/ getProd.asp?xml=/publicaciones/xml/3/29293/ P29293.xml\&xsl=/de/tpl/p9f.xsl\&base=/tpl/ top-bottom.xslt. Acesso em : 10.abr.2009.

2008. Panorama de la inserción internacional de América Latina y El Caribe 2007. Tendencias 2008. Disponível em : http:// www.eclac.org/cgi-bin/getprod.asp?xml=/ publicaciones/xml/9/34329/P34329.xml\&xsl=/ comercio/tpl/p9f.xsl\&base=/comercio/tpl/topbottom.xsl. Acesso em : 10.abr.2009.

OBSERVATÓRIO POLÍTICO SUL-AMERICANO. 2008. Banco de Eventos OPSA. Disponível em : http://observatorio.iuperj.br/ banco.php. Acesso em: 23.nov.2008. 


\section{INTEGRATION AND DEVELOPMENT IN MERCOSUL: DIVERGENCES AND CONVERGENCES IN LULA AND KIRCHNER GOVERNMENT ECONOMIC POLICIES}

\section{Javier A. Vadell, Bárbara Gomes Lamas and Daniela M. de F. Ribeiro}

The early $21^{\text {st }}$ century is witness to the rise to power of new leftist and center-left governments in South America which have at least two common traits: the questioning of pro-market policies and reforms which were carried out over the preceding decade and the return of the State as a central actor in economic life. In spite of this convergence, a deeper analysis would allow us to perceive a certain heterogeneity in the programmatic and organizational character of the new progressive governments. In this regard, we propose an analysis of the responses to the crisis of neo-liberalism that the Brazilian and Argentine governments have provided, placing special emphasis on economic development policies and their implications for regional integration. This more systematic analysis enables us to see that Argentina and Brazil have made different choices regarding what type of policies they have adopted. Brazil has resorted to more orthodox practices such as restrictive monetary policies meant to contain inflation, while Argentina has preferred more heterodox methods such as price controls and export restriction, as well as other policies that encourage consumption. To a certain degree, the differences between the choices made can be attributed to the very economic and political trajectory of each country: pro-market reforms were more intense in Argentina than in Brazil, which meant, regarding productive structure, greater de-industrialization and the extinction of several developmentalist institutions.

KEYWORDS: Argentina; Brasil; development policy; regional integration; comparative economic policy. 
INTÉGRATION ET DÉVELOPPEMENT DANS LE MERCOSUR : DIVERGENCES ET

\section{CONVERGENCES DANS LES POLITIQUES ÉCONOMIQUES SOUS LES} GOUVERNEMENTS LULA ET KIRCHNER

Javier A. Vadell, Bárbara Gomes Lamas et Daniela M. F. Ribeiro

Le début du XXIème siècle est témoin de l'ascension au pouvoir de nouveaux gouvernements de gauche et de centre-gauche en Amérique du sud, qui ont au moins deux caractéristiques en commum : la mise en question des politiques et réformes favorables au marché survenues dans les années précédentes et le retour de l'État en acteur central de la vie économique. En dépit de ce point commum, une analyse plus approfondie nous permet de remarquer cette hétérogéneité de nature programmatique et organisationnelle des nouveaux gouvernements progressistes. En ce sens, nous proposons d'analyser les réponses données par l’Argentine et le Brésil à la crise du néolibéralisme, en soulignant les politiques économiques pour le développement et ses retombées concernant l'intégration régionale. Cette analyse plus pointue nous permet de comprendre que l'Argentine et le Brésil ont fait des choix différents en ce qui concerne le type de politique à adopter. Le Brésil a fait appel à des actions plus orthodoxes, comme les politiques monétaires restrictives pour contrôler les expectatives d'inflation, tandis que l'Argentine a préféré les mesures hétérodoxes, comme le contrôle de prix et la restriction aux exportations, ainsi que d'autres politique d'encouragement à la consommation. D’une certaine façon, la différence entre les choix peut être attribuée à la trajectoire économique elle-même et à la politiques des deux pays : les réformes en faveur du marché, par 
exemple, ont été plus intenses en Argentine qu’au Brésil, ce qui a entraîné, en ce qui concerne la structure productive, une plus forte désindustrialisation et l'extinction de certaines institutions pour le développement.

MOTS-CLÉS : Argentine ; Brésil ; politiques de développement ; intégration régionale ; politique économique comparée. 